\title{
THE END OF 'BERLUSCONISM'?
}

\author{
ANGEla CoSSIRI, GIovanNi Di CoSImo*
}

\section{SIC TRANSIT GLORIA MUNDI}

In the spring of 2008, when a centre-right political alliance largely won the election, it seemed that it would rule through the entire term of the legislature, until 2013. Instead, the adventure of the fourth Berlusconi Government was over long before. The majority had flaked off bit by bit and at the end, on November 8th of last year, the Chamber of Deputies vote on the general statement of the State certified its dissolution. The day after, the President of the Italian Republic Giorgio Napolitano appointed the economist Mario Monti senator for life, adopting "an act of constitutional fantasy, in the days when Berlusconi temporised on his resignation, while the markets were demanding a replacement. Thus, Napolitano, using his prerogative (the power of appointment of senators for life) immediately showed the way and the parties followed" (M. Ainis, Corriere della Sera, 17/11/2011). In fact, Berlusconi tended his resignation soon after. Monti was appointed to form a new Government, which also received an ample parliamentary vote of confidence (on November the 17th in the House of Deputies and the 18th in the Senate).

In the keynote address to the Senate, Monti speaks of a Government of national commitment "created to deal with a serious emergency situation in a unified and constructive spirit". The circumstances of the birth of the Monti Government are exceptional, related to the turmoil in the financial markets and the intensification of the economic crisis. This opens an unprecedented step that marks a clear break with the characteristics that political and institutional life had taken in recent years. Although it is too early to describe the characteristics of the new phase, we can highlight three points which justify this assessment of discontinuity.

The first: the Government is supported by political forces that have so far been active on opposing sides, in particular, Berlusconi's party and the main opposition grouping, the Democratic Party. These parties have opposed

DOI: $10.2478 /$ wrlae-2013-0020

* Angela Cossiri is Researcher in Public Law and Giovanni Di Cosimo is Professor of Constitutional Law, in the Department of Law, University of Macerata. The article is the result of a joint work of the two authors; however, G. Di Cosimo wrote paragraphs 1-4, A. Cossiri paragraphs 5-8. giovannidicosimo@tin.it 
each other since, in the mid-nineties, most of the Italian political system was divided into two factions contending for leadership of Government - the socalled bipolarism. The fact that these parties now support the same Government is even more significant considering that an extreme view of the bipolar system has been established, characterised by harsh confrontation between majority and opposition and exacerbated by continuous polemic fighting and the difficulty of achieving bipartisan policies. This allows us to observe, among other things, that the birth of the new Government has not led to the suspension of democracy, as Mr. Berlusconi said, but of the limitation of competition between the parties (R. D'Alimonte, Il Sole 24 Ore, 17/11/2011).

The second: in addition to the President of the Council, the ministers of the new Government were chosen from among persons outside the political circuit, because the political parties in their desire to avoid direct responsibility did not want to put their men in the executive. Moreover, despite its technocratic composition, the Government obtained the confidence of the Chambers and is therefore a political government in every respect. The formation of the Government, despite the specificities related to the context of a severe economic crisis and the subsequent choice of a technocratic character for the executive leadership, was performed in full respect of constitutional rules and practices.

The third: the first policies fielded by the Government, from fiscal measures to tackle the crisis to the liberalization of important sectors of the economy, show an attitude aimed at guarding the public interest, as opposed to particular interests or those of small power groups, as had been the case previously.

\section{THE POLITICIANS-DIVAS}

Italy is in a transitional phase between what was seen as a specific conception of politics and institutions (the Berlusconi years) and a new party system, which will probably lead to a different method of institutional functioning. If it is still too early to tell what the outcome of this process will be, something can be said about the season that has ended (although, as in all stages of transition, coexistence of the old and new characteristics exists).

The first characteristic of the Berlusconi era is the enhanced personalization of political life, in the sense that certain people monopolized and dominated the political parties (M. Calise, The Party Staff, 2010). The emphasis on the charismatic element, in turn, helped spark a populist drift, fortunately counterbalanced by a firm reaction on part of public opinion and important sectors of public institutions such as the Constitutional Court and the judiciary. These degenerative aspects concern, in particular, the figure of Berlusconi, who extensively used his own television channels and newspapers to consolidate a direct relationship with the electorate, especially the middle and working classes. All this constituted a clear conflict of interests: a rich and powerful owner of mass communication tools became thanks to the action of these well-orchestrated media - the head of Government, a position in which he continuously took decisions that exerted economic effects on his enterprises. 


\section{THE POLITICAL CLASS}

The second characteristic of the Berlusconi era is a marked political class, very attentive to its own corporate interests and essentially deaf to social needs, especially to the most needy among the population. The most obvious example is the law regarding immunity for institutional holders of important positions ("Schifani Agreement", "Alfano Agreement", the law on legitimate impediment), a series of legislative measures designed to focus on the plight of politicians (one in particular), rather than on other citizens, measures the Constitutional Court has repeatedly censored in the name of the principle of equality. This context of heightened corporatism of the political class also includes a number of economic privileges that politicians have been granted over time, from high allowance charges to annuities.

The theme of self of the political class can also be compared to the electoral law of 2005, which, due to the mechanism of the closed electoral list, allows party leaders to decide who will be elected to Parliament simply by determining the order of candidates on the list (and therefore MPs are not really "elected", but "appointed" by party leaders). This mechanism has additional adverse effects: in particular, it has led to a deterioration in the quality of those elected/appointed, as the party leaders have in many cases chosen people prone to be subservient to their will. A return of transformation results from this, which is the practice under which parliamentarians move from one political party to another for reasons of personal interest.

\section{The Parliament MORTified}

Another characteristic is the dominance of the Berlusconi Government over Parliament, which is manifested particularly in terms of the production of rules under which the legislation of the Government (decreed laws and legislative decrees) are more numerous and often more politically relevant than parliamentary laws. This characteristic emerged some time ago, but has certainly increased in recent years, causing the distortion of the features of the parliamentary form of government outlined by the Republican Constitution.

Another cause of the prevalence of the Government is the practice of presenting amendments which completely rewrite all of a given text under discussion in Parliament (the so-called maxi-amendment), and of linking the question of confidence with the approval of these amendments, with the result that a legislative text that comes entirely from the Government is approved.

\section{THE CONSTITUTION UNDER SIEGE}

In the Berlusconi era, criticism of the Constitution went far beyond the matter of physiological tension between law and politics. This veritable siege of the Constitution is the result of two deviant factors. On the one hand, there exists a generalized deficiency of constitutional culture among politicians, who declared that parts of the Constitution may be altered without changing its overall design. In particular, the need to modernize the section 
on powers was discussed without reference to the part on rights, as if the discipline of form of government, even in the most minute details ensuring the principle of separation of powers, was not directly linked to the form of the state and ultimately the protection of rights. On the other hand, there has been a serious misunderstanding of the function of constitutions (and the ultimate meaning of constitutionalism), by which rights are not perceived as the norm and as limitations set on power, but rather as a means of solving problems that affect the political system. But if the problem of Italian politics is a highly fragmented party system whose coalitions are not at all cohesive and in fact locked in constant dispute, the solution can not lie in strengthening the powers of the President of the Council, as has been continuously maintained.

Proof of the assault on the Constitution is the large number of bills pending in the Constitutional Parliament; in the first three years of the current legislature, 329 proposed constitutional amendments were counted, an average of 2 per week This was a slight decrease from the previous term, which had counted 238 in two years (N. Cottone, Il sole 24 ore, 26/4/2011). These are mostly proposals of parliamentary initiative, as if an uncontrollable and all-powerful reformist instinct had taken control of the legislators and had sparked the fantasies of individual MPs and Senators.

The Council of Ministers rapidly approved constitutional law proposals of great material significance: in the last month alone, following the Constitutional "Alfano Agreement", the government launched the reform of articles 41, 97 and 118, the reform of Title IV of justice, the Calderoli draft on the institutional architecture of the State, the abolition of the Provinces and the introduction of the balanced budget constraint. Reforms sometimes unscrupulous both in the statement of principles - often inconsistent with the culture of modern constitutionalism - as well as deprived of the instruments necessary to be effective.

The siege of the Constitution by the Government became particularly insistent with reckless constitutional reform of the entire Part II of the Constitution, that on powers, which at the time was blocked by the referendum of 2006. With this reform, Italy would have found a way out of the constitutional state of law (R. Bin, www.astridonline.it, 2004): the idea was simply to change the rules of the organization of constitutional powers by abandoning the form of parliamentary government, without, however, turning to a different model; to increase the powers of some organs, in particular those of the President of the Council of Ministers, as well as to weaken the organs of control and warranty, thereby jeopardizing the separation of powers and the logic of checks and balances typical of contemporary constitutionalism.

\section{CONSTItUTIONAL REFORMisM}

If the reform of the entire Part II of the Constitution was rejected by the citizenry, other changes have come about with the consent of broad Parliamentary support (for example, the reform of article 51 in terms of equal opportunities for men and women, largely ineffective for its purpose, or the introduction of foreign jurisdiction, or the questionable grant of the right to 
vote to Italians residing abroad who do not pay taxes in Italy). Behind this constitutional reform which permeated the Berlusconi era lies a paradox, since the objectives, proclaimed and remained unfulfilled in many cases, could be achieved not through the medium of the constitutional amendment, but rather through the adoption of ordinary laws, reform of parliamentary regulations or even only in practice. For example, the much-reviled perfect bicameralism, in which the two chambers have exactly the same powers, is not a constitutionally-mandated solution; the Chambers could well differentiate their functions by virtue of modest regulatory and conventional changes, for example, by simplifying approval procedures in the second Chamber; the proclaimed promotion of federalism could be consistently pursued by less centralist government policies; more effective protection of competition could be achieved by giving the Antitrust authorities greater powers, instead of considering amending art. 41 of the Constitution.

In short, there was a symbolic use of constitutional reforms, unsupported by the political will to really address the critical issues. The constitutional reforms made it possible to play the "strong decision-maker" in the face of problems that nobody wanted to or could resolve, due in part to the lack of political unity in the governing majority. The insistence on constitutional reforms has had among its most deleterious consequences the daily de-legitimization - no less risky than the reckless reforms previously mentioned - of Fundamental Law, which has come to be perceived more often as an "antique", rather than as a defense of fundamental rights which are alive and kicking and functioning effectively. The loss of credibility of constitutional rules is not only a cultural problem of sociological significance, but also a legal problem, because it is the consensus that holds the key to the whole system: the Constitutional Court, as we know, does not issue rulings enforced with the use of coercion.

\section{THE RIGHTS UNDER ATTACK}

Another aspect that has in large part characterized recent years is the attack on fundamental rights. This emerges clearly from the most recent constitutional jurisprudence, which has often touched the heart of the political culture of the Berlusconi era. Firstly, the Court has spoken on public safety one of the areas in which there were several decrees issued -with such rulings as that on the illegality of the automatic application of precautionary measures of preventive detention, introduced by the CD "security package" of 2009, with reference to certain crimes against sexual freedom and voluntary homicide. However, a 2011 ruling pertains to another cornerstone of security policy, namely the expansion of the power of mayoral ordinances (the provision contested by the Court allows mayors, as government officials, to take measures of indefinite normative content and effectiveness in order to prevent and eliminate serious threats to urban safety, even in cases not involving violence or urgency).

Those elements of national security affecting the legal status of foreigners are particularly constitutionally critical. In 2010, the Court ruled against the punishment of a foreigner for non-fulfillment of a deportation order whenever a "justification" exists, for example, "an extreme state of 
poverty". The classification of a clandestine immigrant as an aggravation has also been decreed unconstitutional, a measure which was introduced with the CD "security package" in 2008 (judgment n. 245/2001). The prosecution of illegal aliens in Italian legislation has also interested the EU Court of Justice in the El Dridi judgment of April 27, 2011. The Court of Justice rejected imprisonment as an alternative to deportation as dysfunctional and ill-suited to the objective of ensuring the efficiency of policies regulating migratory flows, which instead should be governed by rational rules and with respect for fundamental rights.

An attempt at discriminating against foreigners in the provision of social welfare services is made visible when examining constitutional jurisprudence. In 2008, the Constitutional Court declared unconstitutional two provisions excluding the granting of a care allowance to non-EU foreigners just because they do not meet the income requirements set by the resident permit; the Court declared it is manifestly unreasonable to subordinate the attribution of the provision of care to the possession of a certificate of entitlement to permanence of stay in Italy, which requires, among other things, that the applicant enjoy an income. This incongruence affects the right to health care, intended as the right to possible and partial remedies to impairments produced by more serious pathologies.

With reference to the issue of financial necessity as a justification of the horizontal and indiscriminate budgetary "cuts", the intervention of the Court on the right to education of the disabled must be kept in mind as undertaken in verdict $n$. 80 of 2010 . This ruling censured the "cut" of support teachers contained in the financial budget of 2008 by holding that it had been decreed in violation of constitutional and international legal norms. In remarking on the discretion of the legislature in determining the thresholds for the protection of fundamental rights, the Court said such "is not absolute and is limited by the unfailing respect of a nucleus of guarantees for the persons concerned."

Finally, on the international front, the European Court of Human Rights judgment rendered on 16 July 2009 in the Sulejmanovic case concerning the conditions of imprisonment must be noted, as it turns a spotlight on a dramatic issue that is almost completely absent from public debate.

\section{ETHICS IMPOSED}

A final area in which there has been an alarming level of aggression against freedom is that of "ethically sensitive issues" which affect the effectiveness of protection of fundamental rights. A prime example is the 2004 law on medically assisted procreation, which sought to impose a certain view of ethics and contains many prohibitions and requirements. The event culminated with a ruling that declared unconstitutional legislation which prohibited the creation of a number of embryos greater than three. The Constitutional Court struck down the provision insofar as it does not provide that the transfer of embryos should be carried out without affecting women's health. 
However, it is probably the "Englaro" case and the subsequent story of the parliamentary bill on the regulation concerning prior consent to treatment which marks the darkest and most illiberal page in the history of the Italian Parliament. With reference to this tragic story, concerning a young woman in a state of permanent unconsciousness whose father had asked permission to cease force-feeding, considering it an aggressive therapy, the House and Senate attempted to spark a jurisdictional dispute in the Constitutional Court against the ruling of the Supreme Court which had permitted the termination of medical treatment; this ended with the inevitable decision of inadmissibility of the appeal. In the ensuing legislative activity, the Senate debated and approved a bill prohibiting the refusal of artificial nutritional and hydration treatment in advance directives, so that - if the legislative process were to result in passage - such measures would be legally compulsory, even against an individual's objections. 